\title{
Turismo comunitário, tradicionalidade e reserva de desenvolvimento sustentável na defesa do território nativo: aventureiro-Ilha Grande/RJ
}

\section{Community tourism, tradition, and sustainable development reserve defending native territory: aventureiro (Ilha Grande - RJ)}

\section{Turismo comunitario, tradicionalidad y reserva de desarrollo sostenible en defenza del territorio nativo: aventureiro-Ilha Grande/RJ}

\section{Helena Catão Henriques Ferreira ${ }^{1}$}

\begin{abstract}
Resumo: Este trabalho tem como objetivo desenvolver uma reflexão em torno da ideia de Turismo Comunitário ou de Base Comunitária a partir de uma análise do que ocorre hoje na Vila do Aventureiro-Ilha Grande, Rio de Janeiro e suas relações com o processo de recategorização da área para Reserva de Desenvolvimento Sustentável-RDS, recentemente criada (2014). O turismo que ocorre no Aventureiro é hoje considerado como comunitário, ou "de base comunitária" por ser promovido e organizado exclusivamente pelos moradores nativos e por articular a noção de "populações tradicionais" para garantir seu direito ao território. Nesse sentido, a recategorização da área para Reserva de Desenvolvimento Sustentável - RDS tem uma relação reflexiva com este tipo de turismo, em que cada um alimenta o outro. Este texto se baseia em duas pesquisas qualitativas com perspectiva etnográfica, desenvolvidas nos períodos: de 2003/2004 e de 2008 a 2010. Procurou-se captar a percepção da população local sobre sua experiência com o turismo, as sociabilidades emergentes nesse processo, a forma nativa de enfrentamento das dificuldades advindas com a implantação de uma unidade de conservação restritiva em seu território, e, em contrapartida, suas estratégias inovadoras de sustentação econômica e manutenção da cultura.
\end{abstract}

Palavras-chave: Turismo comunitário; Reserva de Desenvolvimento Sustentável; Tradicionalidade; Cultura Local; Territorialidade.

Abstract: This work aims to develop a reflection around the idea of Communitarian, or Community-based Tourism stemming from an analysis of what goes on today in the Vila do Aventureiro - Ilha Grande, in the state of Rio de Janeiro, and how it relates to the process of recategorizing the area for the Sustainable Development Reserve (RDS), currently underway in the Legislative Assembly of the State of Rio de Janeiro. The tourism which occurs in Aventureiro is today considered as communitarian, or "community-based", for being promoted and

1 Doutora em Ciências Sociais pela Universidade Federal Rural do Rio de Janeiro-UFRRJ, Professora do Departamento de Turismo da Faculdade de Turismo e Hotelaria da Universidade Federal Fluminense-UFF, Coordenadora do Grupo de Pesquisa (CNPQ) Turismo, Cultura e Sociedade. E-mail: lelecatao@gmail.com 
organized exclusively by the native residents and for articulating the notion of "traditional populations" so as to guarantee their right to the territory. In this sense, the recategorization of the area for the Sustainable Development Reserve (RDS) has a reflexive, interdependent relationship with this type of tourism. The work is based upon two qualitative researches from an ethnographic perspective developed along the periods of 20032004 and 2008-2010, and capturing the perception of local population about their experience of tourism, as well as the social relations which emerged in this process, the native ways of facing the difficulties brought up by the creation of a restrictive protected area in their territory, and on the other hand, the innovative strategies for sustaining their economy and maintaining their culture.

Keywords: Community Based Tourism; Sustainable Development Reserve; Tradition; Local Culture; Territory.

Resumen: Este trabajo tiene la finalidad de desarrollar una reflexión en torno de la idea de Turismo Comunitario o de Base Comunitaria a partir de un análisis de lo que ocurre actualmente en la Vila do Aventureiro -Ilha Grande, Rio de Janeiro y sus relaciones con el proceso de re-categorización del área para Reserva de Desarrollo Sostenible-RDS, recientemente creada (2014). El turismo que ocurre en el Aventureiro es ahora considerado como comunitario, o "de base comunitaria" por ser promovido y organizado exclusivamente por los moradores nativos y por articular la noción de "poblaciones tradicionales" para garantizar su derecho al territorio. En este sentido, la re-categorización del área para Reserva de Desarrollo Sostenible - RDS tiene una relación reflexiva con este tipo de turismo, en el que cada uno alimenta al otro. Este texto se basa en dos pesquisas cualitativas con perspectiva etnográfica, desarrolladas en los períodos: de 2003/2004 y de 2008 a 2010. Se trató de captar la percepción de la población local sobre su experiencia con el turismo, las sociabilidades emergentes en ese proceso, la forma nativa de enfrentar las dificultades advenidas con la implantación de una unidad de conservación restrictiva en su territorio, y, en contrapartida, sus estrategias innovadoras de sustentación económica y mantención de la cultura.

Palabras Clave: Turismo Comunitario; Reserva De Desarrollo Sostenible; Tradicionalidad; Cultura Local; Territorialidad.

\section{INTRODUÇÃO}

Como expressivo fenômeno do mundo contemporâneo, o turismo também está articulado pelas redes globalizadas do capitalismo, reproduzindo, como outras atividades econômicas, problemas ambientais e desigualdades sociais. Entretanto, algumas de suas modalidades, sobretudo as que têm foco nas especificidades dos espaços locais, voltadas para a produção em escala artesanal, perseguem as possibilidades de um desenvolvimento diferenciado, no qual estariam envolvidos os mais diversos segmentos sociais. Estas modalidades, em momentos anteriores consideradas como alternativas, e agora muitas delas abarcadas pelo mercado, são, no entanto, passíveis de integrar parcelas da população que até então não se relacionavam com o turismo nem como produtoras e nem como consumidoras.

É importante esclarecer de início, que as experiências hoje denominadas como turismo comunitário ou turismo de base comunitária e que têm se multiplicado e expandido em vários territórios contemporâneos, são de tipos diversificados, não sendo possível enquadra-las em um 
só campo de ação ou mesmo de investigação.

Entretanto, se há algo comum a todas elas é o fato de tentarem de alguma forma responder a diversas questões colocadas pela noção de sustentabilidade, paradigma contemporâneo inspirador de ações de desenvolvimento no mundo, principalmente após os anos 1990, pelo menos no campo da utopia. Um dos aspectos importantes da noção de desenvolvimento sustentável do turismo, mas que por muito tempo não ocupou a centralidade nas discussões e nas ações empreendidas é justamente o que diz respeito às interações sociais relativas a esta atividade.

A crítica central feita à atividade turística a partir do olhar das ciências sociais foi, desde o momento que esta passou a ser um objeto de interesse deste campo de estudos, o foco economicista e prioritariamente mercadológico que imperava não só na produção científica sobre o tema, como também na maioria dos projetos elaborados para as áreas que se pretendiam turísticas. Por outro lado, foi se tornando evidente a assimetria de poderes nas relações entre aqueles que empreendiam muitos dos projetos turísticos e as populações das áreas onde estes eram implantados, frequentemente deixadas de fora destes empreendimentos.

Outra das preocupações importantes foram as "interferências" culturais das populações "visitantes" sobre as "visitadas", tidas muitas vezes como desagregadoras. Longe de serem vistas como "troca cultural" estas relações eram consideradas como imposições de lógicas urbanas, capitalistas e contemporâneas sobre sociedades locais constituídas por valores mais "tradicionais", em que a solidariedade, a cooperação e a reciprocidade eram aspectos fundamentais na garantia da sobrevivência.

Na vila do Aventureiro, Ilha Grande, no litoral sul do estado do Rio de Janeiro, em função da existência da Reserva Biológica Estadual da Praia do Sul, o turismo se desenvolveu de modo diferente que na maior parte das outras vilas da Ilha. Em primeiro lugar, lá não se verifica a intensa especulação imobiliária que ocorre na Ilha, já que a legislação da Reserva Biológica restringiu a ocupação. Em segundo lugar, o tipo de turismo ali realizado, em que os visitantes são geralmente "mochileiros" interessados em acampar em um local de "natureza preservada", se diferencia do que ocorre em outras praias na Ilha Grande, cuja atividade turística demanda maiores investimentos como pousadas, bares e restaurantes, e outros equipamentos para atender às classes média e alta.

A ideia de que o turismo do Aventureiro caracteriza-se como de "base comunitária" surge por ser sua operação e administração feitas pela própria população, que encontrou nessa atividade um meio de vida. A atividade tornou-se importante localmente devido à perda das práticas agrícolas e extrativistas e às restrições à pesca, possibilitando, em grande medida, uma ascensão social das famílias, com o crescimento das possibilidades de trabalho para seus membros, na medida em que esta se organizou em base familiar (Costa, Catão \& Prado, 2009).

Mesmo esse turismo incipiente e organizado de forma artesanal que ocorre no Aventureiro provocou inúmeros conflitos com os órgãos ambientais, pois em alguns momentos teve um crescimento tido como excessivo para ser admitido no esquema de "tolerância vigiada" com que 
estes órgãos passaram a lidar com o problema.

Este trabalho tem como objetivo desenvolver uma reflexão em torno da ideia de Turismo Comunitário ou de Base Comunitária a partir de uma análise do que ocorre hoje na Vila do Aventureiro-Ilha Grande, Rio de Janeiro e suas relações com o processo de recategorização da área para Reserva de Desenvolvimento Sustentável-RDS, recentemente criada (2014).

\section{EXPERIÊNCIAS DIVERSIFICADAS E DIVERSIDADE DE PERSPECTIVAS}

Como dito no início deste texto, não é possível tratar o turismo comunitário como um fenômeno homogêneo, devido a enorme diversidade de formas em que se estrutura, na tentativa de aproveitar os recursos locais e resolver problemas sociais específicos. No entanto, o que se mostra patente é a amplitude e a multiplicidade das ações que se classificam nesta categoria em diversos locais em todo o mundo.

Sampaio (2008) localiza que o desenvolvimento da ideia de um turismo "de base comunitária" no Brasil teve origem de forma mais específica a partir de um diálogo científico que se estabeleceu no I Encontro de Turismo de Base Local, na USP em 1997. No entanto, deriva-se de modalidades já existentes anteriormente como turismo cultural, turismo étnico, agroturismo, etc., formas consideradas como "turismo alternativo". Estas se estabeleceram como estratégias de populações "tradicionais" que ao mesmo tempo em que se apropriam de uma racionalidade hegemônica, privilegiam os ganhos coletivos (Sampaio, 2005, apud Sampaio 2008).

No Brasil tem se desenvolvido uma grande variedade de projetos e tem se ampliado intensamente o número de pesquisas sobre o tema. Pode-se citar como uma experiência pioneira em "turismo de base comunitária" como tal, a da Prainha do Canto Verde, no Ceará (Almeida, 2002; Mendonça, 2004, 2009) que hoje se ampliou abrangendo diversas comunidades parceiras por meio da na Rede Cearense de Turismo Comunitário - Rede TUCUM. Sansolo e Bursztyn (2009) identificaram, em mapeamento do turismo comunitário no Brasil, a existência de casos desta modalidade em todas as macrorregiões brasileiras, com destaque para alguns projetos já com alguns anos de experiência bem sucedida, entre outros ainda em início. A maior parte da pesquisa empreendida por eles abrangeu a região Nordeste do Brasil, onde este tipo de turismo se encontra em maior escala, principalmente os estados do Rio Grande do Norte, Ceará, Paraíba e Pernambuco. Mas foram visitadas, também, outras localidades em que já se desenvolve de alguma forma o turismo comunitário, como: a Vila de Picinguaba, em Ubatuba/São Paulo, a Vila de Trindade em Paraty, a aldeia indígena Guarani Araponga, o quilombo do Campinho, a comunidade caiçara da Reserva Ecológica da Juatinga, também em Paraty, a Reserva Extrativista de Curralinho, em Rondônia, a Reserva de Desenvolvimento Sustentável de Mamirauá, no Amazonas e também projetos na Chapada dos Veadeiros, em Goiás, em quilombos próximos ao Parque Nacional do Jalapão, no estado de Tocantins, na Chapada Diamantina, Bahia, na serra catarinense, em Santa Catarina, entre outros menos conhecidos (Sansolo e Bursztyn, 2009). Algumas características marcantes da maioria dos projetos/ ações são de que muitos deles estão associados a unidades de 
conservação da natureza, principalmente as de Uso Sustentável, como Reservas Extrativistas RESEX e Reservas de Desenvolvimento Sustentável-RDS e também por estarem localizados geralmente em pequenos povoados, aldeias e vilas, nunca abrangendo todo um município, embora não tenham uma dimensão territorial muito definida (Sansolo e Bursztyn, 2009).

Pimentel (2009) apresenta diversos projetos e experiências de hospedagem familiar, que por suas características enquadram-se no perfil descrito como turismo de base comunitária, que apresentam como traço distintivo a importância dada ao acolhimento e à hospitalidade ao visitante, de maneira semelhante a algumas experiências portuguesas, guardadas as devidas diferenças. Neste caso enquadram-se a associação de agroturismo "Acolhida na Colônia", em Santa Catarina, os programas de "Cama e Café", no Espírito Santo, no Rio de Janeiro e em Pernambuco, bem como o "Cama, Café e Rede", da região sertaneja do Rio Grande do Norte. De maneira diferente, pois que com uma caracterização mais urbana, mas também se identificando como turismo comunitário o "Projeto Favela Receptiva", na Vila Canoas e Vila Pedra Bonita, na cidade do Rio de Janeiro. A autora cita ainda as pousadas domiciliares de Fernando de Noronha.

Um caso emblemático de turismo de base comunitária no estado do Rio de Janeiro é o da Vila do Aventureiro, na Ilha Grande, onde desde 1981 foi criada uma Reserva Biológica abrangendo o território da população caiçara (3\% da área total da reserva). De 2008 a 2014 essa pequena área passou por um processo de recategorização para Reserva de Desenvolvimento Sustentável - RDS, recentemente criada. Os moradores vivem atualmente de um turismo peculiar, onde os únicos meios de hospedagem são campings em seus terrenos (Costa, Catão \& Prado, 2009). No restante da Ilha, embora de forma diferente desta vila, existem diversas formas de hospedagem de estrutura familiar, em que a simplicidade e a rusticidade são elementos marcantes (Ferreira, 2010).

Em todo o Brasil multiplicam-se exemplos de empreendimentos que podem ser assim identificados, alguns formalmente estabelecidos em projetos específicos e outros que ainda não se distinguem como tal.

Experiências em diversos países do mundo demonstram o alcance do turismo comunitário, principalmente junto a populações atingidas por fragilidades sociais. Na América Latina a REDTOURS - Rede de turismo comunitário de América Latina reúne uma gama representativa e crescente de países e atores/agentes deste segmento. No Brasil além da Rede TUCUM, há também a Rede brasileira de turismo comunitário - TURISOL.

Nos países de língua portuguesa, diversos investimentos têm sido feitos por governos e comunidades no sentido de desenvolver o turismo de modo que as populações mais pobres possam se inserir criativamente como sujeitos no processo, inventando formas da atividade mais adequadas às suas necessidades.

Em Moçambique o turismo comunitário está principalmente voltado a projetos de turismo de natureza, como a organização de comunidades para o ecoturismo em Maputo ou o do Parque Nacional das Quirimbas no distrito de Ibo, patrocinado pela WWF. Outros parques e reservas também desenvolvem projetos deste tipo, como a Reserva do Niasa e o Parque Nacional de 
Gorongosa, procurando ressaltar a identidade cultural das comunidades e sua relação histórica com os ecossistemas. A estratégia para a conservação da natureza no país tem procurado associar a organização de comunidades para a participação na gestão das áreas protegidas, como indicado pelo Plano estratégico para o desenvolvimento de turismo em Moçambique (2004-2013).

Um estudo sobre o impacto do turismo em regiões insulares da África foi empreendido através de um projeto do CEA - Centro de Estudos Africanos, intitulado "O Impacto do Turismo no Desenvolvimento Comunitário em África: análise de experiências". A análise comparativa tomou por base dois Pequenos Estados Insulares da África Subsahariana (PEI), que reúnem um conjunto de traços comuns, apesar das particularidades que os diferenciam. Os países estudados foram: Cabo Verde e São Tomé e Príncipe. Este trabalho considerou que devido às condições geográficas e ambientais, paisagísticas e socioculturais locais, o turismo se constitui em uma opção estratégica para a redução da pobreza e a promoção do desenvolvimento comunitário. Contudo, identificou que o investimento no setor, a implementação dos projetos e os efeitos resultantes têm evidenciado diferenças significativas nos casos analisados, porém, em todos eles, as iniciativas turísticas influenciam profundamente os modos de vida das populações locais.

Em Portugal o turismo comunitário está mais associado ao turismo rural que ocorre nas aldeias como Lindoso, Branda da Aveleira, Cabração, Castro Laboreiro, Sistelo, entre outras, e também ao agroturismo, ressaltando o aspecto cultural, o patrimônio arquitetônico secular e a hospedagem familiar. Apesar do turismo rural ou "de habitação" em Portugal se dividir entre casas rústicas e casas apalaçadas, em que os proprietários variam entre descendentes de camponeses com algumas posses e outros de uma antiga nobreza de província, há espaço também para criadores de animais e agricultores que procuram rentabilizar antigas instalações agrícolas através do turismo (Silva, 2009). Autor de uma etnografia sobre o turismo rural em Portugal, Luis Silva (2009) que estudou as aldeias de Monsaraz, Sortelha e Estorãos, aponta que este tipo de turismo tem estimulado outras atividades como artesanato, produtos locais e gastronomia tradicional, contribuindo também para a autoestima e os sentimentos de pertença locais, alimentando a esperança em um futuro melhor para estas populações. Embora muito diferentes entre si, todos os processos citados compartilham situações e problemas semelhantes e, certamente, intercambiáveis.

A experiência brasileira tem demonstrado que alguns dos atributos importantes deste tipo de turismo são a autonomia e o protagonismo das populações locais no desenvolvimento da atividade. Ao contrário de lógicas perversas que ocorrem em grande parte da operação do turismo em macro escala, no qual as populações locais se integram (quando se integram) de forma subalterna, no turismo que se pretende "de base comunitária" seu papel central vai desde a organização e eleição de elementos mais adequados e desejados, até os ganhos com a atividade. A escolha e determinação dos recursos a serem utilizados - humanos naturais e patrimoniais -, neste caso, são feitas tomando-se prioritariamente os interesses coletivos do grupo social em questão, mesmo que articuladas aos interesses do mercado globalizado e não exclusivamente para atender às demandas deste último. 
Nesse sentido, um importante aspecto é o de que o turismo comunitário ressalta o modo próprio de cada comunidade entender e fazer o turismo, sua criatividade em promover soluções para as demandas contemporâneas a partir de sua própria cultura (Sahlins, 1997). Muitas vezes essa "interpretação local do turismo" (Irving, 2009) ou os padrões em que este tipo de turismo é operado, expressos em rusticidade e simplicidade, são entendidos, a partir de um ponto de vista etnocêntrico do mercado turístico, como falha ou inadequação. Mas, certamente, tem crescido o contingente de turistas que buscam justamente o contraste da vida simples do campo com seu cotidiano urbano, complexo e "equipado".

Por outro lado, tem sido necessário o desenvolvimento de uma mentalidade cooperativa e associativa capaz de superar o excessivo foco na competitividade e no individualismo presentes nas sociedades contemporâneas. Este aspecto tem sido talvez o maior gerador de dificuldades dos projetos, pois, muitas vezes, as exacerbadas aspirações de crescimento individual comprometem os interesses das coletividades. Este permanece como sendo um grande desafio a ser enfrentado.

A criação de associações, cooperativas e redes tem sido a solução encontrada para a superação do problema e tem se constituído não só numa forma de colocação dos pequenos empreendimentos na disputa perante o mercado turístico, como também na visibilidade frente ao Estado para a obtenção de subsídios e infraestruturas necessárias, mas, sobretudo, no exercício e no aprendizado da ação coletiva.

Outra importante característica do turismo comunitário é a pequena escala dos empreendimentos, geralmente de estrutura familiar, aproveitando equipamentos utilizados pela própria família ou comunidade, implicando menor impacto construtivo. Na medida em que são valorizados elementos culturais e naturais da vida local, a pressão por modificações no espaço e na paisagem é reduzida. Por outro lado, valores como hospitalidade, respeito a tradições culturais, identidades e pertencimentos locais, proteção ambiental e participação social fazem parte de um vocabulário e de um ideário comum aos projetos deste tipo.

\section{LIMITES E POSSIBILIDADES DO TURISMO COMUNITÁRIO}

Diversos limites têm sido levantados a partir de experiências de turismo comunitário no Brasil e no mundo. A partir de uma pesquisa sobre o caso da Nicarágua, Maria José Zapata et al.(2011) demonstram que, apesar da grande ênfase atual sobre o turismo comunitário como indutor de desenvolvimento em comunidades pobres, tem-se verificado um baixo impacto econômico em termos de trabalho e renda, decorrente da pequena escala dos empreendimentos, da falta de habilidade das comunidades para tornar o negócio rentável e também pela monopolização dos benefícios por elites locais (Zapata et al, 2011). Neste estudo foram analisados diversos modelos locais em que se organiza o turismo comunitário, dividindo-os naqueles em que a organização se dá "de cima para baixo", a partir de incentivos e orientação de atores externos às sociedades locais e outros, em que se dá "de baixo para cima", a partir de iniciativas e investimentos das sociedades locais. Os primeiros visariam fortemente o mercado externo, 
enquanto os segundos o turismo doméstico. Foi verificado que o segundo modelo obteve resultados mais positivos em termos econômicos, fazendo conexões com as cadeias produtivas locais da economia informal (Zapata et al, 2011). Outra consequência positiva teria sido a forte apropriação local sobre os projetos de turismo comunitário. As comunidades criaram produtos apropriados para sua capacidade de produção e distribuição, fazendo-o de modo autônomo, com seus próprios conhecimentos e redes disponíveis.

Na maioria dos projetos "de cima para baixo" o turismo é induzido por agentes externos, bem como as decisões e ações são implementadas sob controle externo. A maior parte da oferta foi dirigida a turistas voluntários dos países de origem, ONGs que apoiam os projetos, e aos parceiros das cooperativas agrícolas nos mercados internacionais com interesse em cooperativismo, comércio justo ou produção orgânica de alimentos. A conexão com mercados de longa distância também está relacionada à ideia de que a abertura, a liberalização comercial e as exportações, assim como o turismo internacional são fundamentais para a redução da pobreza e o crescimento econômico (Zapata et al, 2011).

Mielke \& Pegas (2012) argumentam que a maioria dos projetos de turismo comunitário está envolvida em questões limitantes como: o acesso ao mercado, a governança interna e a gestão das parcerias de interesse. Problemas relacionados a estes fatores, na perspectiva dos autores, tem feito com que muitos projetos sejam fracos ou insustentáveis em longo prazo (Mielke, 2009 apud Mielke \& Pegas, 2012). Faltaria, neste caso, metodologia adequada a conduzir o processo, trabalhando a organização comunitária para comercializar seus produtos e serviços e também na distribuição e uso dos lucros. Os autores defendem, ainda, que as linhas teóricas a orientarem os projetos envolvem as discussões de desenvolvimento endógeno, "de baixo para cima" e processos de aglomeração como clusters, arranjos produtivos locais, etc., vistos como pilares de sustentabilidade do turismo comunitário, dependente do desenvolvimento de processos de cooperação (Mielke \& Pegas, 2012).

Embora não se constitua em fator determinante, o turismo comunitário tem sido comumente associado, no Brasil e no mundo, àquele que se desenvolve em áreas rurais, ou de proteção da natureza e muitas vezes em localidades foco de disputas territoriais.

A atividade turística tem sido vista por uma ampla gama de atores, desde setores do Estado quanto das próprias populações locais, como uma forma de ativação de economias rurais afetadas pelo confronto com processos de urbanização, mecanização da lavoura, fracasso da atividade pesqueira, entre diversas outras atividades e mazelas.

Um dos segmentos do turismo que tem sido tratados em diversos países, e de maneira mais incisiva pela União Européia, como importantes para o desenvolvimento local é aquele associado ao meio rural. Tal fato ocorre com o objetivo de fazer frente à depressão econômica e demográfica em que mergulharam muitas de suas áreas, principalmente devido à perda da importância econômica da agricultura.

$\mathrm{O}$ apelo ao reencontro com a natureza e respeito ao meio ambiente associa-se a um movimento de crítica à ideia de progresso contínuo que, desde os primórdios da industrialização 
no mundo, permeou o pensamento hegemônico. Neste sentido, a representação do campo como a "anticidade" se tornou um fator de transformação do próprio campo, da produção de um novo modo de morar (Mathieu, 1998). O rural se associa, então, às noções de paisagem e de patrimônio, transformando-se em um bem a ser conservado e a agricultura passa a ser pensada como mais do que uma atividade produtiva, uma atividade gestora de natureza (Mathieu, 1998). A agricultura se define não por sua função alimentar, mas por gerar uma paisagem, um meio natural, o campo ou a ruralidade (Mathieu, 1998).

De acordo com Wanderley (2000) estariam associadas a este "renascimento rural" as questões relativas ao meio ambiente, as representações a respeito do território nacional, o papel da agricultura no desenvolvimento, como também a busca de soluções para as crises sociais de emprego, e as transformações estruturais dos setores agrícolas e industriais nas sociedades.

Carneiro (1998) chama a atenção para o fato de que a pluriatividade, ainda que não seja uma novidade na vida rural, adquire novas dimensões, na medida em que abre possibilidades de novas formas de organização da produção ou de ressignificação de antigas práticas. Sendo assim, é possível pensar a ruralidade "como um processo dinâmico de constante reestruturação dos elementos da cultura local, com base na incorporação de novos valores, hábitos e técnicas" (Carneiro, 1998, p.61).

É relacionado com o aspecto de pluriatividade no campo que o turismo comunitário se transforma em uma importante atividade para as pequenas comunidades rurais e litorâneas e os pequenos empreendimentos de base familiar.

Mas não só territórios nas áreas rurais se voltam para o turismo de base comunitária. Outras experiências, como por exemplo, em tribos indígenas, ou outros grupos que põe em relevo a questão da etnicidade ou mesmo experiências em favelas urbanas têm procurado se voltar para a perspectiva "comunitária", que, como para Bauman (2003), se constitui a partir de uma coesão social que se dá em relação a objetivos e projetos em comum.

\section{METODOLOGIA DA PESQUISA}

Este trabalho desenvolve uma reflexão sobre Turismo Comunitário ou de Base Comunitária a partir de uma análise do que ocorre hoje na Vila do Aventureiro-Ilha Grande, Rio de Janeiro e suas relações com o processo de recategorização da área para Reserva de Desenvolvimento Sustentável-RDS, que tramitou desde 2010, na Assembleia Legislativa do Estado do Rio de Janeiro, sendo concluído em 2014, com a criação da RDS Aventureiro. Para além do interesse nos aspectos econômicos do turismo de base comunitária, procurou-se captar a percepção da população local sobre sua experiência com o turismo, as sociabilidades emergentes nesse processo, a forma nativa de enfrentamento das dificuldades advindas com a implantação de uma unidade de conservação restritiva em seu território, e, em contrapartida, suas estratégias inovadoras de sustentação econômica e manutenção da cultura.

Baseia-se em duas pesquisas qualitativas com perspectiva etnográfica, desenvolvidas nos 
seguintes períodos: a primeira em 2003/2004 e a segunda entre 2008 e 2010. Optou-se pela abordagem qualitativa, em primeiro lugar, por sua adequação à investigação acerca de um universo de significações, motivos, aspirações, atitudes, crenças e valores. Outra razão significativa é a importância que ela confere à interação entre pesquisador e pesquisado, fator que propicia uma comunicação mais intensa com os sujeitos da pesquisa (Goldenberg, 2003; Beaud \& Weber, 2007; Minayo, 2011).

$\mathrm{Na}$ primeira foram entrevistados 41 moradores da Vila do Aventureiro, entre jovens, adultos e idosos. A segunda pesquisa voltou-se para a participação e gravação de reuniões do processo de recategorização da unidade de conservação e do projeto "O Povo do Aventureiro: fortalecimento do turismo de base comunitária", desenvolvido pela Universidade Federal Rural do Rio de Janeiro-UFRRJ, além de terem sido também entrevistadas 25 pessoas, entre moradores, funcionários do órgão estadual ambiental que administra a unidade de conservação e professores da UFRRJ. Foram utilizadas entrevistas em profundidade e observação direta abordando, entre outras questões de caráter sociocultural, o turismo de base comunitária e o processo de recategorização de unidade de conservação.

Utilizando técnicas de observação direta, atentou-se para as relações sociais entre os moradores, privilegiando o olhar para o seu cotidiano. Foi possível observa-los durante períodos de baixa estação em suas atividades agrícolas e de pesca e interagindo com os turistas, durante o período de alta estação, assim, como também durante a Festa de Santa Cruz, padroeira local, em que reverenciam suas tradições, com uma grande amostragem da população reunida.

Com o propósito de captar mudanças nas formas de vida e de delimitação dos territórios nativos indagou-se sobre as práticas produtivas, costumes e representações simbólicas sobre o espaço e a natureza antes do estabelecimento da unidade de conservação e da chegada do turismo. Para tanto, utilizou-se técnicas de construção de histórias de vida e de história oral, visando apreender fragmentos de memória coletiva sobre o passado da comunidade.

O estudo voltou-se, em seguida, para o período pós-implantação da reserva biológica e pós-afluência de turistas - período este que se prolonga até os dias atuais. Além de procurar identificar as regulações impostas pela legislação nesta nova circunstância, buscou-se perceber o ponto de vista nativo sobre esse conjunto de normas e sobre as alterações e adaptações implementadas em seus modos de vida. A esta dinâmica associa-se a relação destes habitantes com os turistas, como eles os veem, o que identificam como fator de mudança em suas vidas a partir desta presença, qual sua expectativa em relação a eles - em particular face ao fato de estar ocupando um espaço interdito, o que lhes foi historicamente cobrado pelo órgão ambiental responsável pela área. Finalmente o estudo enfocou as reações e relações vinculadas ao processo de recategorização e ao projeto da universidade, em que atores externos passam a propor novas interferências em seu modo de vida, voltando-se para a construção de novos projetos, o da criação de uma RDS e o da formatação do turismo de base comunitária a ela associado e em que seriam necessários a coesão social e o estabelecimento de um sistema de governança consolidado. 


\section{TERRITORIALIDADE INSUSTENTÁVEL E INSTABILIDADE RECORRENTE}

Desde 1981, a área que corresponde à Praia do Aventureiro fez parte da Reserva Biológica da Praia do Sul. Esse fato acarretou inúmeros problemas, tanto para a população, que lá estava muito antes da reserva ser criada, como para o próprio Estado. A primeira passou a ter restrições e impedimentos às suas práticas culturais costumeiras de uso dos recursos naturais e ocupação do espaço. Já o Estado teve que gerir uma complicada situação, criada por ele mesmo, de ilegalidade em relação à reserva, na medida em que a presença de moradores em uma unidade de conservação da categoria Proteção Integral implicou a ocorrência de inumeráveis ações em desacordo com a legislação (Costa, 2004 e 2008; Ferreira, 2004). Várias vezes, a população esteve sob a ameaça de ser retirada do Aventureiro. E, outras vezes, foi aventada a possibilidade de desafetação da área do Aventureiro da Reserva Biológica.

A Vila do Aventureiro localiza-se na parte sudoeste da llha Grande, a maior do estado do Rio de Janeiro. Sua área inclui uma pequena praia com cerca de $800 \mathrm{~m}$ e as encostas dos morros circundantes. Ali reside uma população que, em 2009 contava com cerca de 100 moradores e que está estabelecida no local pelo menos há mais de um século e meio. Estes habitantes que viveram durante longo tempo exclusivamente de uma agricultura voltada ao autoconsumo e da pesca artesanal, presenciaram, a partir de 1994, ou melhor, da desativação do presídio de segurança máxima que havia na Ilha, a intensificação da atividade turística. O turismo em toda a Ilha Grande se expandiu de forma intensa a partir deste período e representa hoje a principal atividade econômica local, interferindo decisivamente em sua organização social e territorial.

A Ilha foi, um dia, coberta pela Mata Atlântica, que sofreu muitas modificações a partir de diversos ciclos econômicos, como plantações de cana de açúcar e de café, criação de gado, especulação imobiliária e mais recentemente, turismo. O Aventureiro se manteve mais conservado, em primeiro lugar por situar-se no lado oceânico, com uma acessibilidade dificultada pelas difíceis condições do mar, o que em algumas épocas do ano praticamente impede a navegação e pelo relevo montanhoso. Outro fator que contribuiu para o relativo isolamento desta área foi a criação da reserva biológica, com uma área de 3600 ha.

Reserva biológica é o tipo mais restritivo de unidade de conservação, não admitindo a presença humana, a não ser de pesquisadores e de seus administradores. Se por um lado esta unidade de conservação impediu que a especulação imobiliária e as ocupações irregulares com alto padrão construtivo, que transformaram a paisagem da llha, se expandisse também pelo Aventureiro e pelas praias do Leste e do Sul, por outro, passou dificultar a sobrevivência da população.

Por diversas vezes foi cogitada sua transferência para outro local, o que só não ocorreu devido a mudanças políticas no órgão ambiental, com a hegemonia (temporária) de um grupo que pretendeu retirar a área do Aventureiro do território da reserva, mantendo a população em suas terras. Esta decisão foi baseada em visões ambientalistas que admitiam os direitos da população nativa ao seu território, mas que encontraram sempre muita resistência institucional. Toda esta 
controvérsia veio se atualizando nas diversas gestões do organismo público e fez com que a população do Aventureiro tivesse que enfrentar permanentes conflitos com o Estado e com "ambientalistas preservacionistas" ${ }^{2}$, muitos deles de dentro do próprio órgão, que nunca se conformaram com sua permanência na área.

\subsection{Recategorização: Solução Ou Inquietação?}

Em fevereiro de 2006, uma força-tarefa governamental pretendeu impedir o funcionamento de estabelecimentos não legalizados na llha e restringir a visitação durante o carnaval. A Vila do Aventureiro tornou-se um dos focos principais da operação, pois os campings, únicos meios de hospedagem no local, não podiam ser legalizados por estarem em área de reserva biológica. Esse contingente atuou de forma agressiva, removendo turistas à força para o continente, e, como coroamento de suas ações, foi decretada a proibição da atividade turística na localidade. Contribuiu também, para todo esse processo, uma reportagem publicada no jornal "O Globo" sobre o que denominou de "práticas predatórias ao meio ambiente da Ilha Grande", enfocando os moradores do Aventureiro.

A partir desse momento, tanto a ideia de remoção da população da praia do Aventureiro, como a desafetação da área da reserva biológica, voltaram a ser postas em pauta. Em resposta a todo esse processo, os moradores, com o apoio de ONG's locais, pesquisadores e até mesmo de turistas, em março de 2006, instauraram inquérito civil junto ao Ministério Público Estadual. No documento esclareciam sua antiguidade no local, muito anterior à criação da unidade de conservação e denunciavam a situação de insegurança em que viviam devido às frequentes ameaças de remoção, demonstrando seu desejo de que o turismo passasse a ser organizado e controlado, e solicitando que a vila do Aventureiro fosse excluída da área da Reserva Biológica da Praia do Sul.

Este movimento resultou na assinatura de um termo de compromisso entre os órgãos públicos e a Associação de Moradores e Amigos do Aventureiro, regularizando, temporariamente, a permanência da população na área da Reserva Biológica da Praia do Sul e o trabalho com o turismo de forma controlada. Desde então, nos períodos de alta estação, como de modo geral o verão, e ainda, o carnaval, a Semana Santa, e alguns feriados, os visitantes precisam fazer um registro no órgão municipal de turismo, que regula, dessa maneira, o número máximo estabelecido em 560 turistas/dia no Aventureiro.

No termo de compromisso, esse esquema teria um caráter provisório valendo até que fosse feita a recategorização da área. A ideia, desde esse momento, foi criar uma unidade do tipo "Uso Sustentável" que admitisse a permanência dos moradores. O turismo, a partir de então, deveria ser organizado e adequado às especificidades da unidade de conservação.

2 Apesar destes ambientalistas se autodenominarem conservacionistas, entendo que sua prática seja inspirada por uma ética de preservação, motivo pelo qual me refiro a eles no texto como "ambientalistas preservacionistas". Na gramática ambiental, a diferença entre preservação e conservação é que a primeira supõe intocabilidade e a segunda, o manejo da natureza no sentido de conservá-la. 
Em janeiro de 2008 teve início uma série de reuniões dos órgãos públicos com a população do Aventureiro, das quais participaram também Ongs e pesquisadores, com o objetivo de discutir a recategorização da área. Em abril deste mesmo ano foi criado o "Grupo de Trabalho do Aventureiro", composto pelos órgãos ambientais estaduais para coordenar todo esse processo.

Duas questões eram centrais para a criação da RDS Aventureiro: a primeira é de que existisse uma população tradicional na área e a outra, de que esta desejasse a criação da nova unidade de conservação. Estes, entretanto, nunca foram pontos consensuais nem para os funcionários do governo e tampouco entre os habitantes da pequena vila e em torno disso se deu um acirrado processo de disputa e negociação.

Estes embates demonstraram que, por um lado, o projeto de RDS proposto pelo governo se caracterizava por um caráter mais conservador em relação ao crescimento da vila e a expansão do turismo, e por parte da população local havia um desejo, mais explicito para uns e ambíguo para outros, de ingresso nas demandas contemporâneas de negociação da terra por seu valor de troca e de ampliação dos negócios do turismo, tendo como norteador, também, o desejo de "segurança", representado pelo "ser dono da terra em que mora" e "poder manter os filhos por perto". "Ser caiçara" passou a ser ainda mais importante para ter o Direito Real de Uso, documento que vincularia os habitantes à Reserva de Desenvolvimento Sustentável-RDS.

\section{2 "Ser Caiçara": da Desqualificação do Sujeito à Conquista de Direitos e Criação do Produto Turístico}

O território da população do Aventureiro tem se estabelecido em visões socioambientalistas como o de uma população "tradicional caiçara". Esta categoria foi atribuída aos nativos da Ilha Grande por agentes externos à localidade, embora hoje seja, em parte, por eles assumida. São conhecidas como "populações caiçaras" aquelas que ocuparam, desde o início da colonização, o litoral brasileiro, associadas prioritariamente à agricultura itinerante, à pesca artesanal e ao extrativismo vegetal, utilizando-se também da caça como complementação alimentar. Com relação às unidades de conservação, "ser caiçara", ou melhor, "ser população tradicional", e, no caso da Ilha, "ser nativo", confere direitos às populações locais, motivo que, provavelmente, influenciou na aceitação desta denominação. A identidade caiçara se constituiria, então, como relacional à unidade de conservação, aceita quase sempre tacitamente e por vezes explicitamente, juntamente com os princípios de identificação de que é produto (Bourdieu, 2002).

Enquanto estiveram relativamente isolados, estes moradores não precisaram definir-se assim, porém com a criação da reserva e a aproximação dos turistas, esta identidade foi se firmando. Não só porque as identidades se constroem na relação com o outro, no jogo dialético entre semelhança e diferença (Oliveira, 1974), mas, também, pelas inúmeras oportunidades que eles têm vivido de narração do passado e de elaboração de uma memória coletiva, estimulada pelas constantes perguntas dos pesquisadores, dos representantes do Estado, dos ambientalistas e dos turistas. 
Como tratado em outros trabalhos (Ferreira, 2004 e 2010), a noção de "populações tradicionais" tornou-se importante no Aventureiro, pois foi o que permitiu aos habitantes da vila lá permanecerem por todos esses anos. Essa noção tem sido utilizada em diversos "fóruns participativos" e na construção de planos e zoneamentos, para diferenciar direitos territoriais das populações "nativas" em contraste com as sucessivas levas de imigrantes que têm aportado, sendo, porém, muito questionada, por carregar indefinições e ambiguidades.

Foi inicialmente definida no âmbito internacional do debate sobre a relação de alguns grupos sociais com a conservação da biodiversidade, e veio a se firmar, no Brasil, nesse mesmo contexto, a partir das pesquisas de Antônio Carlos Diegues, que se tornou responsável por sua ampliação no meio ambientalista (Barreto Filho, 2006).

Segundo Sant'Anna (2003), a polêmica sobre qual o termo e a definição adequados se estendeu até o momento em que a lei foi sancionada pelo presidente, quando, então, foi vetada. Esse veto deveu-se à dificuldade em se definir o conceito de modo a não cometer injustiças, excluindo grupos pertinentes ou incluindo indevidamente outros.

Diegues deduz que a identidade do indígena no Brasil é definida de forma mais clara do que aquela das "comunidades tradicionais" não indígenas (2001). Desta forma, o reconhecimento dessas identidades coexiste com um debate sobre o significado dos termos populações "nativas", "tribais", "indígenas" e "tradicionais" utilizados internacionalmente (Diegues, 2001).

Alguns outros problemas podem ser apontados em relação ao conceito de "populações tradicionais": em primeiro lugar, a dificuldade na delimitação do que as diferencia de outras sociedades. Como determinar até que ponto uma sociedade inclui-se nos atributos para classificála como tradicional? A noção também pressupõe a ideia de sociedade estática, congelada em determinados padrões, não observando o aspecto dinâmico da reprodução sociocultural. Como observa Zanoni (2000) essa noção gera ambiguidades que podem prejudicar a compreensão das dinâmicas que produzem, reproduzem e transformam os modos de vida de um grupo social. Além disso, pode implicar uma tendência à uniformização de grupos heterogêneos, dificultando a apreensão de sua historicidade. Barretto Filho (2006) argumenta que essa noção conspiraria contra a autonomia desses próprios grupos diante de suas aspirações ao ingresso na modernidade, em relação aos níveis de consumo e bem-estar, por exemplo.

Esse último aspecto parece estar presente no Aventureiro, onde a "tradicionalidade" tem sido incorporada/acionada de forma ambígua. Ao mesmo tempo em que, em alguns momentos, os habitantes afirmam ser caiçaras arraigados ao lugar, em outros reivindicam com veemência a possibilidade de vender suas casas livremente e ir morar no município de Angra dos Reis. O valor percebido como negativo ou positivo em "ser caiçara" pode mudar e de fato tem mudado circunstancialmente.

Além de todas as questões descritas acima, hoje, o turismo se apropriou desta qualificação fazendo com que "ser caiçara" simbolicamente denote "autenticidade", o que passa a constituir um elemento de atratividade da atividade na llha. Donos de pousadas, bares, barcos, agências de turismo, etc. se utilizam desta categoria como instrumento de marketing, na construção de 
produtos turísticos.

O termo que foi, em outros tempos, muito rejeitado, por ser associado ao ignorante, ao sem valor, com uma carga pejorativa semelhante à do caipira (no interior) é recuperado pelo discurso socioambiental e passa a ter um valor positivo, designando o "homem do litoral", o "nativo", aquele que tem ligações identitárias com a agricultura, com o uso da floresta, com a pesca, com o mar. Esse significado é transmitido aos que designa, e estes passam a utilizá-lo na luta por seus direitos, além de servir para reivindicarem um lugar diferenciado no trabalho com o turismo, frequentemente em desvantagem na relação com investidores "de fora".

\subsection{Um Diálogo nem Sempre Fácil e às Vezes Impossível}

O processo de recategorização polarizou um diálogo de visões de mundo muito diferentes e territorializações muitas vezes contraditórias, que já vinha acontecendo, mesmo que não formalmente, desde a criação da reserva e a chegada do turismo (Ferreira, 2004 e 2010). O que diferenciou esse processo do que ocorria anteriormente foi que, em primeiro lugar, nunca antes o estado havia se proposto a escutar as razões e motivos dos moradores. Isso implicou que agora, os representantes dos órgãos ouvissem queixas contundentes, reclamações as mais variadas e se confrontassem com uma mágoa retida por quase trinta anos, que encontrava espaço para se manifestar. Embora se esforçassem por explicar que eram diferentes e este era um novo tempo, para os moradores o tempo passado não havia renovado a situação e o que estava ocorrendo era uma continuidade.

Durante todo esse processo de reuniões e estudos sobre a recategorização, os representantes do Estado, que o conduziram, fizeram apelos à participação dos moradores. Muitas vezes tiveram a impressão de que a população do Aventureiro estava perplexa e calada. Essa impressão provavelmente deveu-se ao fato de que se esperou deles algo que não fazia parte de sua forma de se relacionar com os problemas. A "tradicionalidade" desejada pelos moradores esteve sempre marcada pelas demandas descritas acima. Para os representantes do Estado, que conduziram o processo, entretanto, a intenção era negociar o direito às roças, à pesca e ao turismo, mas de forma irredutível quanto a esses elementos desejados pela comunidade.

Baumam (2005) identifica uma condição eternamente provisória na construção da identidade. No Aventureiro, a identidade que serve politicamente para defender o direito ao território apresenta-se, porém, para parte dos atores em questão, como uma categoria aprisionadora, na medida em que é baseada em uma visão essencialista desse estatuto. Mesmo admitindo atualização (na aceitação de hábitos e costumes contemporâneos) a tradicionalidade é exigida desta sociedade, para que se constitua o direito à permanência numa área destinada à conservação da natureza.

No calor do embate político detonado pela entrada do Projeto de Lei da RDS Aventureiro na Assembleia Legislativa do Rio de Janeiro - ALERJ, e diante dos argumentos de seus opositores, que alegavam que a permanência da cultura local prejudicaria o projeto preservacionista imaginado 
para a área justificando, assim, a retirada da população, a necessidade de defesa da tradicionalidade se reforçava.

Desta forma, atores locais, com perspectivas contrárias à RDS aproximavam-se no campo da luta, por motivos francamente opostos, daqueles que, externamente, combatiam a criação deste novo tipo de unidade de conservação.

\section{CONSIDERAÇÕES FINAIS}

O diferencial do turismo que ocorre no Aventureiro é justamente o fato de ser a própria população local sua produtora e beneficiária. Os moradores locais "inventaram" seu próprio modo de gestão do turismo (Costa, 2004 e 2008; Ferreira, 2004; Costa, Catão \& Prado, 2009). "Seu 'modo de fazer' o turismo é improvisado, baseado e incorporado ao fazer da própria vida" (Ferreira, 2004, p. 54).

O diferencial do turismo que ocorre no Aventureiro é justamente o fato de ser a própria população local sua produtora e beneficiária. Os moradores locais "inventaram" seu próprio modo de gestão do turismo (Costa, 2004 e 2008; Ferreira, 2004; Costa, Catão \& Prado, 2009). "Seu 'modo de fazer' o turismo é improvisado, baseado e incorporado ao fazer da própria vida" (Ferreira, 2004, p. 54).

Por outro lado, o desenvolvimento de uma mentalidade cooperativa e associativa é ainda um grande desafio a ser enfrentado. Na Vila do Aventureiro grande parte das reclamações dos moradores sobre a sociabilidade que surge a partir do turismo é expressa como "hoje em dia é cada um por si", "ninguém mais ajuda o outro como antigamente", apontando para um processo mais competitivo e menos colaborativo quando comparado com "o tempo dos antigos".

Entretanto, a criação de associações, cooperativas e redes tem sido a solução encontrada para a superação do problema e tem se constituído não só numa forma de colocação dos pequenos empreendimentos na disputa perante o mercado turístico, como também para fortalecê-los perante o Estado para a obtenção de subsídios e infraestruturas necessárias, mas, sobretudo, no exercício e no aprendizado da ação coletiva. Esta perspectiva ainda não se verifica localmente. No "projeto da Rural", (como era denominado pelos moradores) estas questões foram abordadas, mas apenas a Associação de Moradores do Aventureiro- AMAV é capaz hoje de representa-los e mesmo assim com certa dificuldade, devido às diferenças e desavenças ocorridas durante o processo de recategorização.

Outra importante característica do turismo comunitário em geral é a pequena escala dos empreendimentos, geralmente de estrutura familiar, aproveitando equipamentos utilizados pela própria família ou comunidade, implicando menor impacto construtivo. Na medida em que são valorizados elementos culturais e naturais da vida local, a pressão por modificações no espaço e na paisagem é reduzida. Por outro lado, valores como hospitalidade, respeito a tradições culturais, identidades e pertencimentos locais, proteção ambiental e participação social fazem parte de um vocabulário e de um ideário comuns aos projetos deste tipo. No Aventureiro este vocabulário 
começa a se fazer presente. Apesar das novas sociabilidades colocadas pela competição implicada no processo turístico, antigos modos de cooperação são observados ainda em momentos de necessidade como doenças ou dificuldades de alguma família em prover seu sustento, na organização que com poucas modificações perpetuam as festas tradicionais e mesmo em colaborações entre famílias nas formas de produção e construção locais.

Atualmente, a expectativa dos jovens locais volta-se para o desenvolvimento do turismo, que mudou radicalmente a vida dos habitantes, possibilitando-lhes adquirir inúmeros bens de consumo que antes não faziam parte de suas vidas. Além disso, conseguiram melhorias nas condições dos barcos, elementos importantes para sua autonomia, além de uma transformação ao nível das relações sociais.

Uma questão que impunha muitos limites ao projeto de turismo comunitário do Aventureiro era o fato de a Vila fazer parte de uma reserva biológica. Hoje, com a RDS criada novas propostas de ordenamento do turismo podem se concretizar. O projeto trabalhado pela Universidade Federal Rural do Rio de Janeiro- UFRRJ levou em conta a precariedade das propostas diante da necessidade de primeiro haver a recategorização da área, pela impossibilidade de serem desenvolvidas em uma reserva biológica. O projeto de RDS, entretanto, considerava o turismo de base comunitária como uma atividade adequada para promover a sustentabilidade econômica da comunidade local, associada às práticas costumeiras de roça e pesca.

Na verdade, o turismo de base comunitária, como descrito, está estreitamente associado à Reserva de Desenvolvimento Sustentável, pois é ela que propõe a garantia de um território para a comunidade local. Hoje com a concretização da RDS novos desafios se apresentam. A capacidade de "inventar" conjuntamente o turismo e a coesão da comunidade necessária para este tipo de turismo é semelhante a que a RDS precisa para se constituir efetivamente, já que é uma unidade de conservação comunitária (de população tradicional). Daí que não só a RDS constitui a base do Turismo de Base Comunitária, como este, da mesma forma, oferece terreno para que a unidade de conservação (que também é sustentável) se sustente.

\section{REFERÊNCIAS}

Almeida, H. L. P. S. (2002) Indicadores de Qualidade de Vida, instrumento para o monitoramento participativo da qualidade de vida de comunidades costeiras tradicionais: O caso Prainha do Canto Verde, Beberibe/CE. (Dissertação de Mestrado Universidade Federal do Ceará, 2002).

Barreto Filho, H. T. (2006) Populações tradicionais: introdução à crítica da ecologia política de uma noção. In: Adams, C.; Murrieta, R.; Neves, W. (Org.). Sociedades caboclas amazônicas: modernidade e invisibilidade. São Paulo: Annablume.

Beaud, S. \& Weber, F. (2007) Guia para a pesquisa de campo: produzir e analisar dados etnográficos, Petrópolis: Vozes.

Bourdieu, P. (2002) O poder simbólico. Rio de Janeiro: Bertrand Brasil. 
Bauman, Z.(2003) Comunidade: a busca por segurança no mundo atual. Rio de Janeiro: Jorge Zahar. (2005) Identidade. Rio de Janeiro: Jorge Zahar.

Carneiro, M.J.(1998) Ruralidade: novas identidades em construção, In: Revista Estudos, Sociedade e Agricultura, no 11. Rio de Janeiro: CPDA/UFRRJ.

Costa, G. V. (2004) A população do Aventureiro e a Reserva Biológica Estadual da Praia do Sul: Conflitos e disputas sob a tutela ambiental. (Dissertação de Mestrado, Universidade Federal do Rio de Janeiro, 2004).

(2008) O Aventureiro, Ilha Grande-RJ: uma análise de mudança social. (Tese de Doutorado, Universidade Federal do Rio de Janeiro, 2008).

Costa, G. V. L.; Catão, H.; Prado, R. (2009) Praia do Aventureiro: um caso sui generis de gestão local do turismo. In: Bartholo, R.; Sansolo D.; Bursztyn, I. (Orgs.). Turismo de base comunitária: diversidade de olhares e experiências brasileiras. Rio de Janeiro: Letra e Imagem.

Diegues, A.C. \& Arruda, R. (2001) Saberes tradicionais. Brasília: Ministério do Meio Ambiente, 2001.

Ferreira, H. C. H. (2004) Redefinindo Territórios: Preservação e transformação no Aventureiro, Ilha Grande, $R J$, (Dissertação de Mestrado, Universidade Federal Rural do Rio de Janeiro, 2004).

(2010) A dinâmica da participação na construção de territórios sociais e do patrimônio ambiental da Ilha Grande-RJ, (Tese de Doutorado, Universidade Federal Rural do Rio de Janeiro, 2010).

Goldemberg, M. (2003) A arte de pesquisar: como fazer pesquisa qualitativa em ciências sociais, Rio de Janeiro: Record.

Irving, M. A. (2009) Reinventando a reflexão sobre turismo de base comunitária: inovar é possível? In: Bartholo, R.; Sansolo D.; Bursztyn, I. (Orgs.). Turismo de base comunitária: diversidade de olhares e experiências brasileiras. Rio de Janeiro: Letra e Imagem.

Mathieu, N. (1998) La notion de rural et les rapports villes-campagnes em France: les années quatre-vingt-dix , Économie Rurale, n. 247.

Mendonça, T. C. M.(2004) Turismo e Participação comunitária: 'Prainha do Canto Verde a "Canoa" que não quebrou e a "Fonte" que não Secou?'. (Dissertação de Mestrado, Universidade Federal do Rio de Janeiro, 2004).

(2009) Turismo socialmente responsável da Prainha do Canto Verde: uma solução em defesa do local herdado. In: Bartholo, R.; Sansolo D.; Bursztyn, I. (Orgs.). Turismo de base comunitária: diversidade de olhares e experiências brasileiras. Rio de Janeiro: Letra e Imagem.

Mielke, E.J.C.\&Pegas, F.V. (2012) Turismo de Base Comunitária no Brasil. Insustentabilidade é uma questão de gestão. Turismo em Análise.

Minayo, M. C.; Deslandes, S., Gomes, R.(2011) Pesquisa Social: Teoria, método e criatividade. Petrópolis: Vozes. 
Oliveira, R. C.(1974) Um conceito antropológico de identidade. Revista ALTER, Brasília: UNB

Pimentel, A. B. Dádiva e hospitalidade no sistema de hospedagem domiciliar. In: Bartholo, R.; Sansolo D.; Bursztyn, I. (Orgs.). Turismo de base comunitária: diversidade de olhares e experiências brasileiras. Rio de Janeiro: Letra e Imagem.

Sahlins, M. (1997) O pessimismo sentimental e a experiência etnográfica: por que a cultura não é um objeto em via de extensão (Parte I). Mana. 3 (1), Rio de Janeiro.

Sampaio, C. A.(2008) Pensando o conceito de turismo comunitário. Artigo apresentado no V Seminário da Associação de Pesquisa e Pós-Graduação em Turismo, Belo Horizonte.

Sansolo, D. G. \& Bursztyn, I. (2009) Turismo de base comunitária: pontencialidade no espaço rural brasileiro. In: Bartholo, R.; Sansolo D.; Bursztyn, I. (Orgs.). Turismo de base comunitária: diversidade de olhares e experiências brasileiras. Rio de Janeiro: Letra e Imagem.

Sant'Anna, R.(2003) Sistema Nacional de Unidades de Conservação: reflexões antropológicas sobre a elaboração de uma lei ambiental. (Dissertação de Mestrado, Universidade Federal do Rio de Janeiro, 2003).

Silva, L. (2009) Casas no campo: etnografia do turismo rural em Portugal, Lisboa: Imprensa de Ciências Sociais.

Wanderley, M.N.B. (2000) A emergência de uma nova ruralidade nas sociedades modernas avançadas Revista Estudos, Sociedade e Agricultura, n. 15, Rio de Janeiro: CPDA.

Zapata, M.J.; Hall, M.C.; Lindo, P.; Vanderschaegue, M. (2011) Can community-based tourism contribute to development and poverty alleviation? Lessons from Nicaragua, Current Issues in Tourism.

Artigo recebido em: 18/11/2013. Artigo aprovado em: 11/09/2014. 